\title{
Comparative Structural and Mechanical Studies on Polyamide 6 Knitted-Reinforced Single Polymer Composites Prepared by Different Reactive Processing Techniques
}

\author{
Shafagh. D. Tohidi $\mathbb{1}^{1},{ }^{1}$ Ana Maria Rocha $\mathbb{D}^{1},{ }^{*}$ Nadya V. Dencheva, ${ }^{2}$ António Sérgio Pouzada, ${ }^{2}$ \\ Zlatan Denchev $\mathbb{1}^{2}$ \\ ${ }^{1}$ Center of Textile Science and Technology (2C2T), Department of Textile Engineering, University of Minho, \\ Guimarães, Portugal
}

${ }^{2}$ i3N - Institute for Polymers and Composites, Department of Polymer Engineering, University of Minho, Guimarães, Portugal

\begin{abstract}
Single polymer laminate composites based on anionic polyamide 6 (PA6) matrix-reinforced by PA6 knitted textile structures (KSPC) were produced by nylon reactive injection molding and powder coating/compression molding (PCCM) processing techniques. The effect of the reinforcement's structure and the fiber volume fraction on the mechanical properties of the knitted-reinforced PA6 composites resulting from the two methods were investigated and compared. The morphology and the crystalline structure of KSPC materials were studied to identify the main factors determining the tensile properties. The results showed that the PCCM method produced laminate composites with higher Young's modulus and mechanical strength in tension. Microscopy, differential scanning calorimetry and $\mathrm{X}$-ray diffraction experiments were carried out to correlate the morphology and crystalline structure of the composites and their precursors with the different tensile behavior of KSPC prepared using the two techniques. The microscopy and X-ray scattering studies suggested the formation of a transcrystalline layer at the matrix/reinforcement interface. POLYM. COMPOS., 40:E886-E897, 2019. @ 2018 Society of Plastics Engineers
\end{abstract}

\section{INTRODUCTION}

Conventional organic polymer composites are produced by combining of chemically different organic or inorganic

Correspondence to: A. M. Rocha; e-mail: amrocha@det.uminho.pt Contract grant sponsor: Fundação para a Ciência e a Tecnologia; contract grant number: LA25/2013-2014POCI-01-0145FEDER-007136; SFRH/ BD/94759/2013; SFRH/BSAB/130271/2017; UID/CTM/50025/2013. contract grant sponsor: European Regional Development Fund. contract grant sponsor: Foundation for Science and Technology; contract grant number: POCI-01-0145-FEDER-007136.

DOI 10.1002/pc.25075

Published online in Wiley Online Library (wileyonlinelibrary.com).

(C) 2018 Society of Plastics Engineers components, whereas the single polymer composites (SPCs) consist of oriented polymer reinforcing elements embedded in an isotropic matrix of the same polymer [1]. The SPC concept was brought forward by Capiati and Porter in 1975 [2] and tested in several polymer systems. SPC were shown to possess good stress transfer between matrix and reinforcements due to the presence of H-bonds or even covalent bonds across the matrix-reinforcements interface, molecular entanglements and/or formation of favorable amorphous/ crystalline superstructures [3,4]. Conversely, conventional thermoplastic composites display weak van der Waals forces acting across the interface that only to a certain extent could be strengthened by surface treatment of the reinforcements or use of appropriate coupling agents. Moreover, the possibility for full recycling through conventional reprocessing is cost-effective for SPC [5], which stimulates the industrial and commercial interests towards these polymer materials.

Polyamide 6 (PA6)-based SPC are typically prepared by melt-processing techniques that may include powder impregnation [6], hot compaction [7,8], overheating of fibers [9], film-stacking [10], and co-extrusion [11]. All these techniques require partial melting of the reinforcing polymeric elements. Thus, a part of the reinforcements always loses its beneficial morphology and/or orientation and may also be subjected to thermal degradation, which, as a rule, leads to inferior mechanical properties.

Applying reactive processing techniques proved well in the preparation of SPC whereby the polymer matrix is synthesized by in-situ polymerization of low-viscosity monomers or oligomers in the presence of the reinforcements $[12,13]$. Activated anionic ring-opening polymerization of lactams (AAROP) is a special case of reactive processing in which cyclic monomers are transformed into high molecular weight polyamides at relatively mild conditions 
and short time durations, without releasing of by-products $[14,15]$. This process requires temperatures in the $160-180^{\circ} \mathrm{C}$ range, thus providing a processing window (PW) of $40-60^{\circ} \mathrm{C}$ for the PA6-based SPC, which is the difference between the AAROP polymerization temperature of $\varepsilon$-caprolactam (ECL) and the melting point of the PA6 reinforcement $\left(220^{\circ} \mathrm{C}\right)$.

In one of the few studies on the preparation of PA6-based SPC, Gong et al. [16] used reactive injection molding (RIM) to prepare SPC consisting of in situ formed PA6 matrix reinforced with PA6 plain woven fabric. The optimum polymerization temperature was found to be $160^{\circ} \mathrm{C}$ that determined a large $\mathrm{PW}$ and ultimate tensile strength of $150 \mathrm{MPa}$. Bhattacharyya et al. [10] prepared PA6-based SPC by a combination of hot compaction and film stacking. Their SPC materials reached tensile strengths of ca. $120 \mathrm{MPa}$, which is a $400 \%$ improvement on the pure PA6 matrix material. However, the $\mathrm{PW}$ of only $2^{\circ} \mathrm{C}$ reported in this case is a limitation for the industrial application of this method.

It seems that only the in-situ creation of the PA6 matrix by a polymerization process in the presence of the reinforcement can provide the necessary PW of the conventional techniques and to optimize the PA6-based SPC preparation. AAROP of inexpensive lactams was a possible reaction pathway. Preparation of PA6-based SPC via inmold AAROP using a semiautomatic prototype equipment was reported by Dencheva et al. [17] who achieved tensile strengths of above $130 \mathrm{MPa}$ and Young's moduli over 1.5 GPa using only $20 \mathrm{wt} \%$ of reinforcement.

Polyamide-based SPC were also produced via reactive microencapsulation of nanoclays in PA6 through AAROP [18]. The resulting nanoclay-loaded microcapsules were further used for powder impregnation of PA66 plain-wave textile structures that were consolidated to all-polyamide laminate composites by compression molding. Studying the mechanical properties in tension, flexure, and impact revealed $73 \%$ improvement of the Young's modulus, up to $142 \%$ increase of the stress at break, and more than a fivefold increase of the notched impact resistance as compared with the neat PA6 matrix.

Notably, no studies on the mechanical behavior of PA6-based SPC as a function of the type and architecture of the reinforcing textile plies have been performed so far. In this study, PA6-based SPC reinforced by several plies of Jersey and Rib $1 \times 1$ knitted structures (designated as KSPC) were produced using two distinct processing methods for the formation of the PA6 matrix: RIM of polyamide-6 (nylon reactive injection molding [NYRIM]) and powder coating/compression molding (PCCM) of PA6 microparticles (MPs), previously synthetized from ECL in suspension by AAROP as described previously in [19]. The tensile properties, morphological characteristics, and crystalline structure of the reinforcements and the PA6-SPC resulting from the NYRIM and PCCM techniques were evaluated and compared.

\section{EXPERIMENTAL}

\section{Textile Reinforcements}

Two commercially available Jersey and Rib $1 \times 1$ knitted fabrics produced with air jet textured PA6 filaments (160 dtex) were selected. All samples were pre-washed with a $1 \mathrm{~g}$. $\mathrm{L}^{-1}$ of a non-ionic detergent solution at $30^{\circ} \mathrm{C}$ for $30 \mathrm{~min}$ and then rinsed with reverse osmosis water for another $15 \mathrm{~min}$ to minimize contamination. To eliminate non-chemically bonded finish from the filaments surface, the knitted reinforcements were immersed in acetone for $30 \mathrm{~min}$ and subsequently dried for $2 \mathrm{~h}$ at $60^{\circ} \mathrm{C}$. To stabilize the geometry of the knitted structure, all reinforcements were extended $30 \%$ of their original dimensions and annealed at $170^{\circ} \mathrm{C}$ for $90 \mathrm{~min}$. Table 1 presents the basic constructional characteristics of knitted reinforcements.

\section{Reagents}

The ECL monomer of reduced moisture (AP-Nylon ${ }^{\circledR}$ caprolactam) was delivered from Brüggemann Chemical (Germany). Before use, it was kept under vacuum for $1 \mathrm{~h}$ at $23^{\circ} \mathrm{C}$. Brüggolen $\mathrm{C} 20$ from the same company (C20) was used as polymerization activator, and according to this manufacturer, it contains $80 \mathrm{wt} \%$ of blocked di-isocyanate in ECL. The initiator sodium dicaprolactamato-bis-(2-methoxyethoxo)aluminate (DL) was purchased from Katchem (Czech Republic) and used without further treatment. The puriss grade of acetone, methanol, toluene and xylene solvents used in this work were purchased from Sigma-Aldrich (USA).

\section{Preparation of KSPC via NYRIM (N-Composites)}

One of the techniques used to prepare KSPC for this study is based on the activated anionic polymerization of ECL and performed with a specially designed prototype

TABLE 1. Sample designation and properties of weft-knitted reinforcements used.

\begin{tabular}{lccccccc}
\hline Reinforcement type & Treatment & Sample Designation & WPC & CPC & Loop Length (mm) & Areal weight $\left(\mathrm{g} / \mathrm{m}^{2}\right)$ & Thickness (mm) \\
\hline \multirow{2}{*}{ Rib $1 \times 1$} & - & R & 16 & 25 & $2.28 \pm 0.04$ & $208 \pm 4$ & $0.79 \pm 0.01$ \\
& Annealed & R-A & 13 & 18 & $2.14 \pm 0.03$ & $108 \pm 2$ & $0.60 \pm 0.01$ \\
\multirow{2}{*}{ Jersey } & - & J & 16 & 30 & $2.10 \pm 0.02$ & $160 \pm 4$ & $0.54 \pm 0.01$ \\
& Annealed & J-A & 15 & 25 & $2.07 \pm 0.02$ & $102 \pm 2$ & $0.41 \pm 0.01$ \\
\hline
\end{tabular}

WPC, Wale per centimeter; CPC, Course per centimeter. 

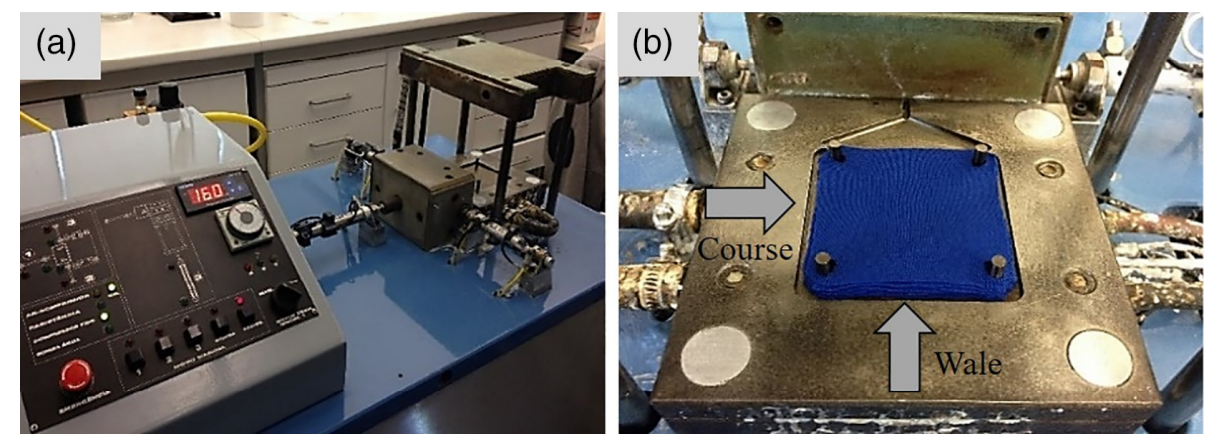

FIG. 1. (a) Prototype equipment for RIM of polyamides (NYRIM). (b) In-mold reinforcement installation with course and wale directions indicated (Adapted from Ref. 20).

equipment developed for NYRIM [20] (Fig. 1a). In a typical preparation, $0.33 \mathrm{~mol} \mathrm{ECL}$ was heated to $90^{\circ} \mathrm{C}$ under nitrogen flux and then $1.5 \mathrm{mmol}$ of the DL initiator were added. After several minutes at temperatures between $90-110^{\circ} \mathrm{C}, 0.75 \mathrm{mmol}$ of activator $\mathrm{C} 20$ was added to the mixture at once. The resulting activated monomer/initiator mixture was injected into the $80 \times 80 \times 3 \mathrm{~mm}$ parallelepiped impression of the mold that was preheated to $120^{\circ} \mathrm{C}$. The annealed reinforcements (R-A or J-A) were already placed in the mold, oriented in the wales direction (0) (Fig. 1b). The polymerization temperature was kept in the range of $160-170^{\circ} \mathrm{C}$, setting the reaction time at $15 \mathrm{~min}$. After that time, the mold was switched automatically to cooling down to $65^{\circ} \mathrm{C}$ at a cooling rate of $40^{\circ} \mathrm{C}$. $\mathrm{min}^{-1}$. The demolding of the laminate plate thus prepared by NYRIM concluded the processing cycle.

\section{Preparation of KSPC via PCCM (P-Composites)}

The solution-precipitation AAROP of ECL to PA6 MPs was performed as described in detail elsewhere [18,19,21-23]. The chemical reaction of AAROP in this study is schematized in Fig. 2. Summarizing the preparation procedure, the amount of $2 \mathrm{~mol} \mathrm{ECL}$ was dissolved in a $1: 1 \mathrm{v} / \mathrm{v}$ toluene/xylene mixture under nitrogen atmosphere refluxing the reaction mixture for $10-15 \mathrm{~min}$. In several minutes, clear solutions were obtained and the components of the catalytic system DL and C20 were introduced in a molar ratio 2:1. The reaction time was $1 \mathrm{~h}$, keeping the temperature in the $125-135^{\circ} \mathrm{C}$ range at constant stirring. Thus, the PA6 MPs were produced in the form of a fine powder, separated from the reaction mixture by vacuum filtration, washed with methanol, and dried.

The KSPC were produced by the PCCM (P-composite) in the following way. The plies of unidirectional R-A or J-A reinforcements and previously calculated amounts of MPs were deposited into the mold before compression molding (Fig. 3). For the preparation of laminate KSPC of $\mathrm{k}$ plies, the MPs were divided into $(k+1)$ equal portions and the respective ply sets were prepared. The consolidation of the ply sets by compression molding was performed in a hydraulic hot press Moore (UK) using a mold with dimensions $70 \times 70 \times 2 \mathrm{~mm}$. The pressure applied was $5 \mathrm{MPa}$ for $10 \mathrm{~min}$ at $215^{\circ} \mathrm{C}$ and the samples were subsequently cooled down to $50^{\circ} \mathrm{C}$ at a rate of ca. $50^{\circ} \mathrm{C} \cdot \mathrm{min}^{-1}$.

All the $\mathrm{N}$ - and $\mathrm{P}$-composites were prepared considering three fiber volume fractions $V_{\mathrm{f}}$, namely 15,20 , and $25 \%$. The required number of textile plies $(N)$ for each $V_{\mathrm{f}}$ value (in \%) was determined according to Eq. 1 [24]:

$$
N=\frac{V_{\mathrm{f}} \cdot \rho_{\mathrm{f}} t}{A_{w}} \times 100
$$

where $\mathbf{A}_{\mathbf{w}},\left(\mathrm{g} . \mathrm{m}^{-2}\right)$ is the area density of the textile reinforcement, $N$ is the number of plies, $\rho_{\mathrm{f}},\left(\mathrm{g} . \mathrm{m}^{-3}\right)$ is the density of the PA6 fibers and $\boldsymbol{t}(\mathrm{m})$ is the laminate thickness. All laminate test samples were cut by laser to the standard dimensions. The designation and description of all KSPC laminates in this study are presented in Table 2.

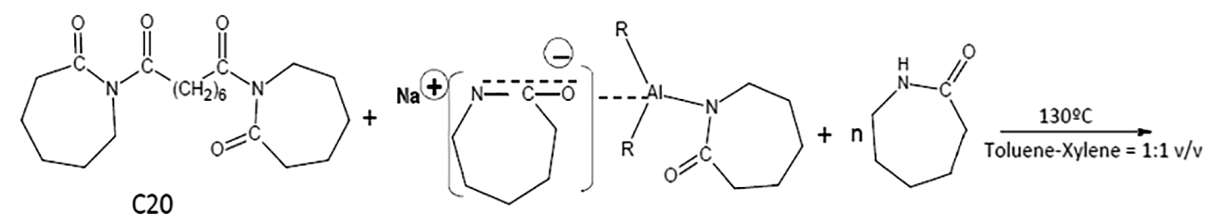

$\mathrm{DL}$

ECL

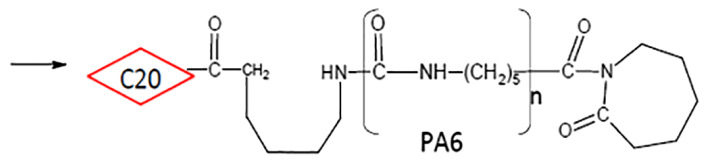

FIG. 2. Chemical reactions occurring during AAROP in solution: C20 Bruggolen C20 (activator), DL dicaprolactamato-bis-(2-methoxyethoxo)-aluminate, $\mathrm{R}=\mathrm{OCH}_{2} \mathrm{CH}_{2} \mathrm{OCH}_{3}$. 


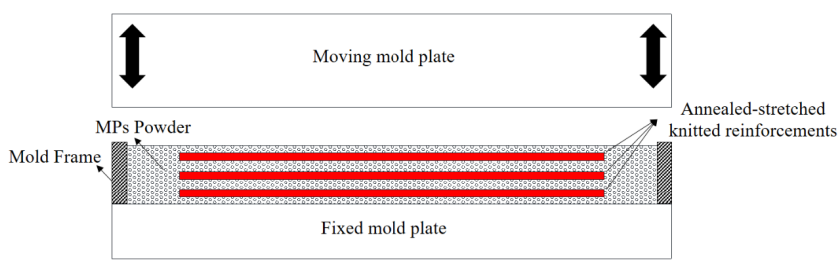

FIG. 3. Installation of the SPC prepreg in the compression mold, adapted from [20].

\section{Morphological Characterization}

Optical and scanning electron microscopy (SEM) studies were carried out to characterize the KSPC materials. An Olympus microscope (BH-2) equipped with an image acquisition software (Leica Application Suite 4.4) and polarized light was used to obtain optical images of the samples, allowing the analysis of the bonding condition at the matrix-reinforcement interface region. The SEM studies were performed in a NanoSEM-200 apparatus of FEI Nova (USA) to evaluate the morphology of PA6 mono-filament/ matrix interface. An Au/Pd alloy was applied to sputtercoat the samples.

The differential scanning calorimetry (DSC) studies were carried out in a $200 \mathrm{~F} 3$ equipment of Netzsch (Germany) at a heating rate of $10^{\circ} \mathrm{C} \cdot \mathrm{min}^{-1}$ under nitrogen purge. To erase the thermal history of the specimens, two consecutive scans were carried out in which the crystallization was performed by cooling at a rate of $10^{\circ} \mathrm{C} \cdot \mathrm{min}^{-1}$. The glass transition temperature, the PWs and the degree of crystallinity were obtained from each the DSC curves. The typical weights of the samples were in the $6-16 \mathrm{mg}$ range. The crystallinity index $X_{\mathrm{C}}(\%)$ of the samples was calculated according to Eq. 2 :

$$
X_{\mathrm{c}}(\%)=\frac{\Delta H_{m}^{i}}{\Delta H_{m}^{\circ}}
$$

where in $\Delta H_{\mathrm{m}}^{\mathrm{i}}$ is the registered melting enthalpy of the current sample and $\Delta H_{\mathrm{m}}^{\circ}$ is the melting enthalpy of a $100 \%$ crystalline PA6 (230 J/g) [25].

TABLE 2. Designation and description of $\mathrm{N}$ - and P-composites.

\begin{tabular}{lcccc}
\hline $\begin{array}{l}\text { KSPC } \\
\text { designation }\end{array}$ & $\begin{array}{c}\text { Knitted } \\
\text { reinforcement } \\
\text { architecture }\end{array}$ & $V_{f},(\%)$ & $\begin{array}{c}\text { Plies } \\
\text { Number } \\
(\text { PCCM) }\end{array}$ & $\begin{array}{c}\text { Plies } \\
\text { Number } \\
\text { (NYRIM) }\end{array}$ \\
\hline P-J-15 & J-A & 15 & 3 & - \\
N-J-15 & & 20 & - & 5 \\
P-J-20 & & 25 & - & - \\
N-J-20 & & 15 & - & 7 \\
P-J-25 & R-A & 3 & - \\
N-J-25 & & 20 & 4 & - \\
P-R-15 & & 25 & 5 & - \\
N-R-15 & & & & - \\
P-R-20 & & & 5 \\
N-R-20 & & & & 8 \\
P-R-25 & & & & - \\
N-R-25 & & & & - \\
\hline
\end{tabular}

Note: The designations $\mathrm{P}$ or $\mathrm{N}$ stand for the PCCM or NYRIM molding techniques used in this study.
The wide-angle X-ray scattering (WAXS) patterns for reinforcements, MPs, neat matrices and $\mathrm{N}$ - and Pcomposites were made on a Bruker D8 Discover $\theta-\theta$ diffractometer working with $\mathrm{Cu} K \alpha$ radiation $(\lambda=1.541 \AA)$. The patterns were collected for all specimens in the $\theta / 2 \theta$ scan regime in the $2 \theta$ range of $5-45^{\circ}$ at a rate of $0.1 \mathrm{deg}$. $\mathrm{min}^{-1}$. The curve fitting of the WAXS patterns was made as previously described in [26] using a commercial peak-fitting software. The WAXS crystallinity index $X_{\mathrm{c}}^{\mathrm{WAXS}}$, was calculated according to Eq. 3:

$$
X_{\mathrm{c}}^{\mathrm{WAXS}}(\%)=\frac{\sum \mathrm{A}_{\mathrm{c}}}{\sum \mathrm{A}_{\mathrm{c}}+\sum \mathrm{A}_{\mathrm{a}}}
$$

where $\sum A_{\mathrm{c}}$ is the integrated area under the respective crystalline peaks and $\sum A_{\mathrm{a}}$ is the integrated area of the amorphous halo(s).

The average viscometric molecular weight $M_{\mathrm{v}}$ of the asprepared MPs and the molded samples thereof was determined by intrinsic viscosity measurements in $97 \%$ sulfuric acid at a concentration of $0.2 \mathrm{~g} / \mathrm{dL}$ with a suspended level Ubbelohde viscometer thermostatted at $25^{\circ} \mathrm{C}$. The MarkHouwink equation for PA6 was used with $K=5.066 .10^{-4}$ and $\alpha=0.74$ [27].

\section{Mechanical Characterization}

The tensile properties of the KSPC laminates were evaluated with samples conditioned for ca. 30 days at $23^{\circ} \mathrm{C}$ and $65 \%$ relative humidity. Tests were performed in an Instron 4505 testing machine at $23 \pm 2^{\circ} \mathrm{C}$ with a standard load cell of $50 \mathrm{kN}$ and at a constant crosshead speed of $2 \mathrm{~mm} \cdot \mathrm{min}^{-1}$. The specimens with a gauge length of $38 \mathrm{~mm}$ were cut out according to ASTM D638. At least five specimens of each sample were tested. The Young's modulus (E) was calculated from the stress-strain curves as the tangent at $1 \%$ strain.

The tensile behavior of the knitted reinforcement was assessed according to ASTM D5034 (grab test). The tensile test was performed in the same Instron 4505 testing machine with a standard load cell of $2.5 \mathrm{kN}$ and at a constant crosshead speed of $2 \mathrm{~mm} \cdot \mathrm{min}^{-1}$. The $150 \times 100 \mathrm{~mm}$ knitted textiles were conditioned at $23^{\circ} \mathrm{C}$ for $5 \mathrm{~h}$ before testing.

\section{RESULTS AND DISCUSSION}

\section{Initial Characterization of MPs and Neat NYRIM Plates}

According to previous works on the mechanism of the AAROP in suspension [28,29], the anion-initiated process creates viscous oligomer droplets formed by the growing PA6 polymer molecules that are dispersed in the solvent. After reaching some critical molecular mass and various acts of coalescence, these droplets crystallize transforming into porous MPs. Figure 4a shows the typical morphology of MPs displaying spheroidal shapes and sizes in the $15-25 \mu \mathrm{m}$ range. The porosity of the MPs can be observed 

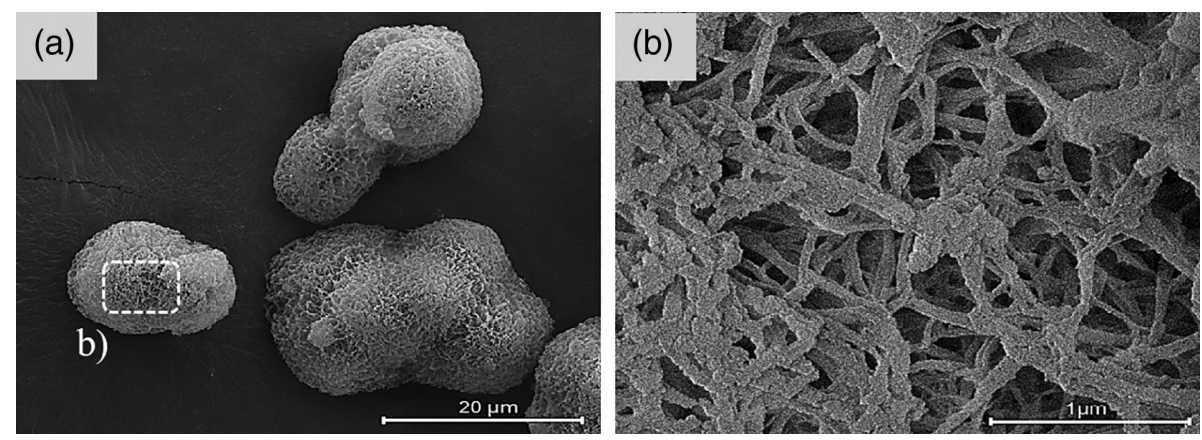

FIG. 4. (a) Selected SEM micrographs of MPs (b) Magnified selected image.

at higher magnifications (Fig. 4b). Our previous studies show that the transformation of the viscous droplets into MPs without the formation of lumps requires an optimized stirring rate of ca. $800 \mathrm{rpm}$, maintaining the molar ratio DL/C20 $=2$ and keeping the temperature of AAROP below $135^{\circ} \mathrm{C}$. The average viscometric molecular weight $M_{\mathrm{v}}$ of the as-prepared MPs was $36,500 \mathrm{~g} / \mathrm{mol}$, which was slightly below the values of the R-A and J-A reinforcements with $M_{\mathrm{v}}$ of ca. $39,500 \mathrm{~g} / \mathrm{mol}$. At the same time, the $M_{\mathrm{v}}$ of the neat PA6 plate without textile reinforcement obtained by NYRIM was ca. $58,000 \mathrm{~g} / \mathrm{mol}$. This difference can be explained with the higher temperature of AAROP in the latter case $\left(160-170^{\circ} \mathrm{C}\right)$ and with the fact that AAROP occurs in bulk, in the polar molten ECL, and in strongly basic medium, without dissolution with inert solvents [30].

\section{Mechanical Properties of the Textile Reinforcements}

The stress-strain graphs of J-A and R-A in wale and course directions are plotted in Fig. 5. The stress-strain curves in either principal direction displayed two zones. The initial zone is a linear segment $(0-5 \%$ strain) used to calculate the Young's modulus (Fig. 5, the inset). The second much broader zone of the curves showed gradual increase of stress (strain hardening) up to the point of

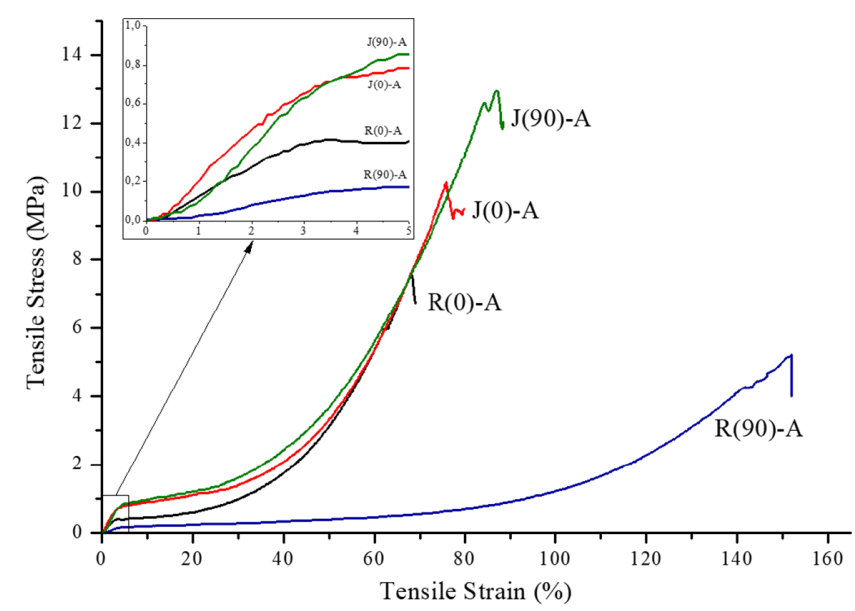

FIG. 5. Stress-strain curves of stretched-annealed knitted reinforcements in the wale (0) and course (90) directions. For sample designation see Table. 1. mechanical failure. The J-A textile has higher E-modulus and tensile strength in either direction. The notable difference in the tensile behavior of R-A textiles in the two principal directions evidences their high anisotropy.

\section{Tensile Properties of KSPC Laminates}

The influence of the knitted reinforcement architecture (R-A and J-A) and volume fraction $\mathrm{V}_{\mathrm{f}}$ on the tensile performance of $\mathrm{N}$ - and P-composites was investigated. Examples of the stress-strain curves obtained in the wale direction are shown in Fig. 6a and b. As it can be observed in Fig. 6a, all P-composites have higher tensile strength and undergo larger strain at rupture as compared with the neat matrix (PN). The reinforcement architecture did not

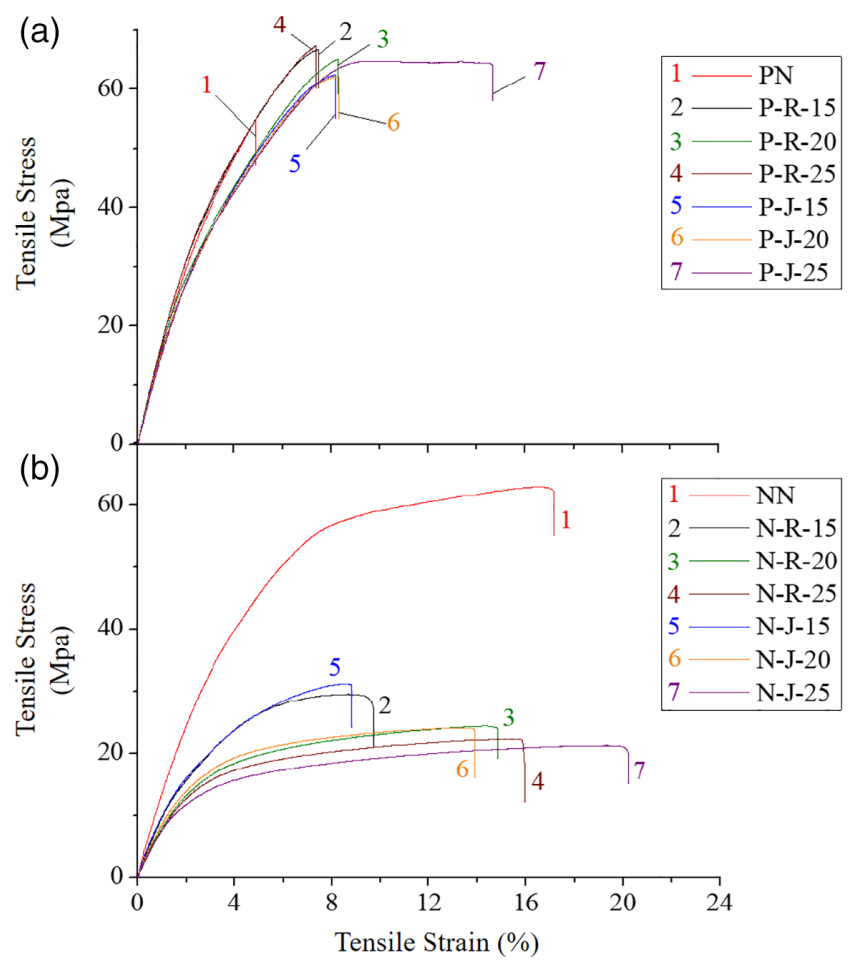

FIG. 6. Stress-strain curves for KSPC with different reinforcement architecture and fiber volume fractions $V_{f}$ prepared by (a) PCCM and (b) NYRIM techniques. For sample designation see Table 2. 
significantly influence the tensile strength of the composites and affects only slightly their tensile deformability. Except for P-J-25 sample, all KSPC in Fig. 6a show a brittle behavior. The increase of $V_{\mathrm{f}}$ also had a minor effect on the tensile performance of the P-composites.

Regarding the tensile properties of $\mathrm{N}$-composites (Fig. 6b), it is apparent that the in-mold polymerization of ECL caused an increase in ductility (from 5 to 17\%) and tensile strength of the matrix component (from ca. $55 \mathrm{MPa}$ to $60 \mathrm{MPa}$ ), as illustrated by the stress-strain curve of the neat matrix $(\mathrm{NN})$. However, the tensile strength of all $\mathrm{N}$ composites was significantly lower than the PCCM samples. The explanation of this experimental result should be related to the finishing of the reinforcing textile structures. It can be hypothesized that irrespective of the preliminary washing, traces of the finishing probably remained on the textile fibers and hindered the sensitive in-mold AAROP process that forms in-situ PA6 matrix during NYRIM. This hindrance resulted in a lower degree of conversion of ECL to high molecular weight PA6 leading to the observed deterioration of the mechanical performance of the N-composites. Since the PCCM samples are produced with already existing PA6 powders, textile finishing does not have any influence there.

The tensile properties of all $\mathrm{N}$ - and $\mathrm{P}$-composites are presented in Table 3. Within the $\mathrm{P}$ - or N-series, the increase of $V_{\mathrm{f}}$ causes the reduction of the $E$-modulus and the raise of the tensile strength and the strain at break of the laminates. In the case of N-composites, a clear increase in the strain at break is observed as $V_{\mathrm{f}}$, increased, together with a drop in the $E$-modulus and tensile strength. In the following sections, morphological, and crystallographic analysis are presented to investigate the possible causes for this behavior.

\section{Morphological and Crystallographic Analysis of KSPC}

Analysis of Fiber-Matrix Interface by Microscopy. In composite materials, the bonding condition at the fibermatrix interface is critical to determine their mechanical

TABLE 3. Tensile properties of $\mathrm{N}$ - and P-composites.

\begin{tabular}{lccr}
\hline $\begin{array}{l}\text { Samples } \\
\text { reference }\end{array}$ & $\begin{array}{c}\text { Young's } \\
\text { modulus E (GPa) }\end{array}$ & $\begin{array}{c}\text { Tensile strength } \\
\sigma_{\max }(\mathrm{MPa})\end{array}$ & $\begin{array}{r}\text { Deformation } \\
\text { at break } \varepsilon_{\text {br }}(\%)\end{array}$ \\
\hline PN & $1.73 \pm 0.02$ & $56.7 \pm 1.8$ & $5.2 \pm 0.1$ \\
NN & $1.38 \pm 0.05$ & $66.2 \pm 2.9$ & $12.1 \pm 1.1$ \\
P-R-15 & $1.93 \pm 0.03$ & $65.5 \pm 1.3$ & $9.2 \pm 0.5$ \\
P-R-20 & $1.68 \pm 0.02$ & $63.9 \pm 1.1$ & $8.5 \pm 0.4$ \\
P-R-25 & $1.77 \pm 0.03$ & $67.8 \pm 1.1$ & $10.3 \pm 0.1$ \\
P-J-15 & $1.66 \pm 0.02$ & $62.1 \pm 0.3$ & $8.9 \pm 0.4$ \\
P-J-20 & $1.61 \pm 0.03$ & $62.3 \pm 0.5$ & $9.7 \pm 0.6$ \\
P-J-25 & $1.65 \pm 0.03$ & $65.3 \pm 0.8$ & $19.8 \pm 0.2$ \\
N-R-15 & $1.04 \pm 0.01$ & $28.9 \pm 0.6$ & $7.1 \pm 0.1$ \\
N-R-20 & $0.83 \pm 0.02$ & $23.9 \pm 0.8$ & $13.3 \pm 1.7$ \\
N-R-25 & $0.77 \pm 0.02$ & $23.5 \pm 0.1$ & $18.0 \pm 0.2$ \\
N-J-15 & $1.08 \pm 0.07$ & $28.8 \pm 0.4$ & $9.2 \pm 1.4$ \\
N-J-20 & $1.02 \pm 0.03$ & $23.8 \pm 1.6$ & $14.1 \pm 0.4$ \\
N-J-25 & $0.89 \pm 0.01$ & $21.8 \pm 0.7$ & $20.8 \pm 0.4$ \\
\hline
\end{tabular}

For sample designation see Table. 2. performance. The preparation of SPC and other polymerpolymer composites frequently includes a stage in which the molten matrix-forming polymer crystallizes epitaxially upon oriented crystalline fibers, whereby a transcrystalline layer (TCL) is formed on the fiber surface $[31,32]$.

The simplest method to detect the formation of TCL is to compare the thickness of the reinforcing monofilaments in the neat textile structure to that in the final laminate composite. Logically, the formation of TCL can be expected if the diameter of the initial textile filaments is smaller than in the final laminate composite. This method was adopted here to analyze PA6-based SPC. Ten readings from various microscopy images were used in either textile structures or SPC.

In Fig. 7a, the polarized light microscopy (PLM) image of the knitted reinforcements shows that the average thickness of the constituent monofilaments is around 17-18 $\mu \mathrm{m}$. The PLM micrographs of the P-composites (P-R-15 and P$\mathrm{J}-15$ samples) reinforced by R-A and J-A are displayed in Fig. $7 \mathrm{~b}$ and $\mathrm{c}$, respectively. The average thickness of the monofilaments in the R-A-reinforced KSPC laminates (P$\mathrm{R}-15$ samples) lies between $22-23 \mu \mathrm{m}$. Thus, the thickness of TCL should be between $2-3 \mu \mathrm{m}$.

Figure $7 \mathrm{c}$ shows that the average thickness of the monofilaments in the J-A-reinforced composites (P-J-15 samples) is between $21-22 \mu \mathrm{m}$, only slightly lower than in the R-Areinforced KSPC. Interestingly, the lower TCL thickness in the J-A-reinforced KSPC correlates with the slightly lower tensile strength and stiffness of these composites as compared with those containing R-A plies.

Figure $8 \mathrm{a}$ and $\mathrm{b}$ displays the PLM images of the Nseries composites, with $15 \%$ of R-A and J-A reinforcements. It can be verified that the average thickness of the monofilaments embedded in $\mathrm{N}$-composites lies between 19-20 $\mu \mathrm{m}$. Since the same textile plies shown in Fig. 7a with thicknesses of 17-18 $\mu \mathrm{m}$ were used in the N-composite, the TCL thickness in the latter should be of $0.5-1 \mu \mathrm{m}$ (Fig. 8a and b). In this context, it can be assumed that based on PLM data, the thickness of the TCL in Ncomposites is lower than in the P-composites. Most probably, the thicker TCL in the P-composites can be related with the higher pressure applied during KSPC consolidation than in the case of NYRIM where the mold closes without exerting any pressure.

The reinforcement/matrix interface microstructure was studied additionally by SEM. The Figure $9 \mathrm{a}$ and $\mathrm{b}$ shows representative SEM images of the P-R-15 and N-R-15 samples cryogenically fractured along the wales $\left(0^{\circ}\right)$ direction.

As it can be observed on Fig. 9a, the P-composites show good matrix impregnation of anionic PA6 matrix among the monofilament. Moreover, there is no sign of melting or surface degradation of embedded monofilaments accompanied by voids and cracks at the filament/matrix interface. Therefore, a strong interfacial bonding may be expected in the P-composites. Thus, it is the textile monofilament that bears the load without being pulled-out from the matrix. Close to the point of its failure, the filament is stressed 

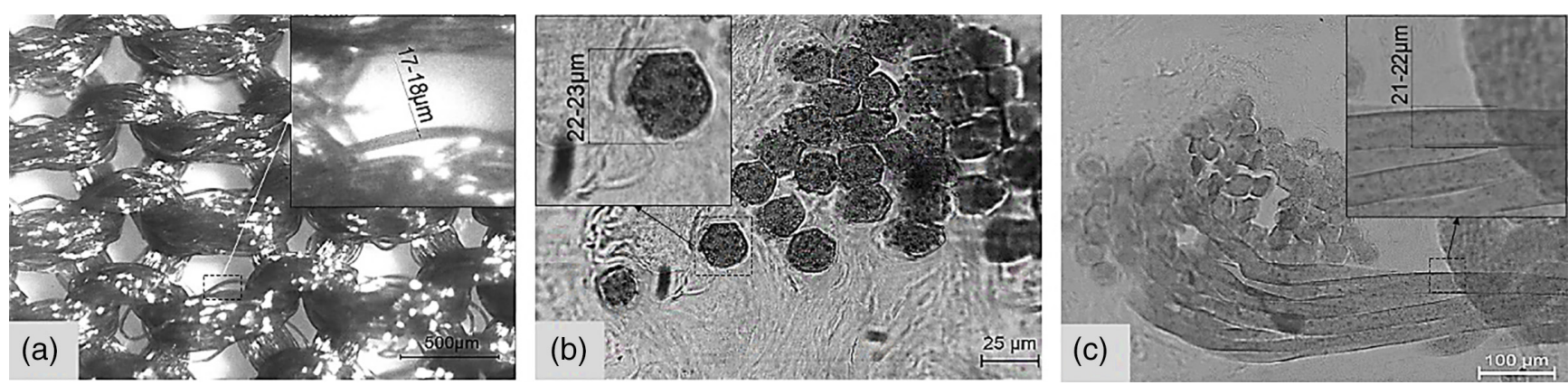

FIG. 7. Selected PLM images of: (a) J-A structure before laminate formation and measuring monofilament thickness (inset); Measuring the thickness of embedded monofilament in (b) P-R-15 laminate composite; (c) PJ-15 laminate composite.

longitudinally, which explains the conical configuration of broken monofilaments (Fig. 9a).

The SEM images of the N-composites (Fig. 9b) display clear microcracks in the regions at the matrix-filaments interface. This behavior is indicative of poor filament/matrix adhesion, which could be one of the reasons that led to insufficient tensile performance of these KSPC. The micrographs in Fig. 9b show a good wetting of the filaments by the matrix material and almost circular cross-section of the broken monofilaments that apparently did not resist the external load efficiently and displayed a fragile failure.

Structural Studies by DSC. DSC experiments were carried out on the textile reinforcements and KSPC prepared by both techniques to better understand the crystalline structure of two KSPC types of this study, as well as to determine the width of the PW. Figure 10a demonstrates the DSC thermogram of the NN and PN matrices, MPs and J-A (first and second scans). In the case of PCCM, the PW is the difference in the melting temperatures $\left(T_{\mathrm{m}}\right)$ values of the PA6 MPs and reinforcement materials, that is in the range of $13-14^{\circ} \mathrm{C}$. For the $\mathrm{N}$-composites, a $\mathrm{PW}$ of ca. $60^{\circ} \mathrm{C}$ is determined, representing the difference between the $T_{\mathrm{m}}$ of the textile reinforcement $\left(223^{\circ} \mathrm{C}\right)$ and the temperature at which AAROP is carried out. Both PWs are significantly higher than that previously found for PA6-based SPC [10]. This fact, as evidenced by the microscopy observations above, apparently solves the problem of the undesirable melting of the reinforcements during the compression molding. Figure 10a and Table 4 confirmed that the $\mathrm{T}_{\mathrm{m}}$ of the PA6 MPs is $207.8^{\circ} \mathrm{C}$, while those of R$\mathrm{A}$ and J-A reinforcements vary in the $223-224^{\circ} \mathrm{C}$ range. This observation could be related to the fact that both textile structures are based on hydrolytic PA6 normally carried out in the melt that is, at ca. $250^{\circ} \mathrm{C}$, whereas the anionic PA6 of the MPs is produced at $130^{\circ} \mathrm{C}$ and in hydrocarbon solution. The slightly lower $M_{\mathrm{v}}$ of MPs in comparison to the R-A and J-A could also be a reason for the lower $T_{\mathrm{m}}$ of the former.

The curves of the first heating show also that the $\mathrm{J}$ and $\mathrm{J}$-A reinforcements displayed some broad low-temperature endothermic peaks centered at $75^{\circ} \mathrm{C}$ (Fig. 10a, Curves 4 and 5) that remained not affected after the annealing with fixed ends at $170^{\circ} \mathrm{C}$ for $90 \mathrm{~min}$ that is, below the $T_{\mathrm{m}}$ of the textile. Since this feature disappeared completely during the second scan performed after complete melting of textiles (Fig. 10a, Curve 6), the corresponding peak was associated to a relaxation processes within the knitted structure occurring right above the glass transition temperature $T_{\mathrm{g}}$.

Comparing the first scan, DSC curves of NYRIM (first $\mathrm{NN}$ ) and PCCM (first PN) neat matrices (Fig. 10a, Curves 1 and 2) show that the PA6 matrices in both cases do not undergo low-temperature crystallization or melting processes. Interestingly, the first scans of the N-J-15 (Fig. 10b, Curve 1) composite contain broad endothermic peaks centered slightly above $100^{\circ} \mathrm{C}$ that disappears during the second DSC scan (Fig. 10b, Curve 3). Analyzing these peaks in conjunction with the morphology and mechanical data,
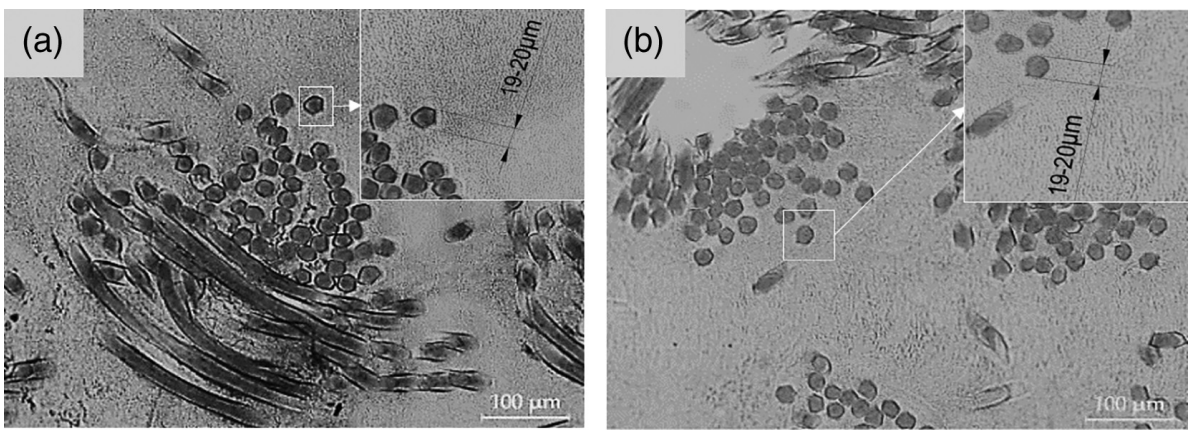

FIG. 8. Microscopy surface topography of N-composites: (a) N-R-15 and (b) N-J-15. 

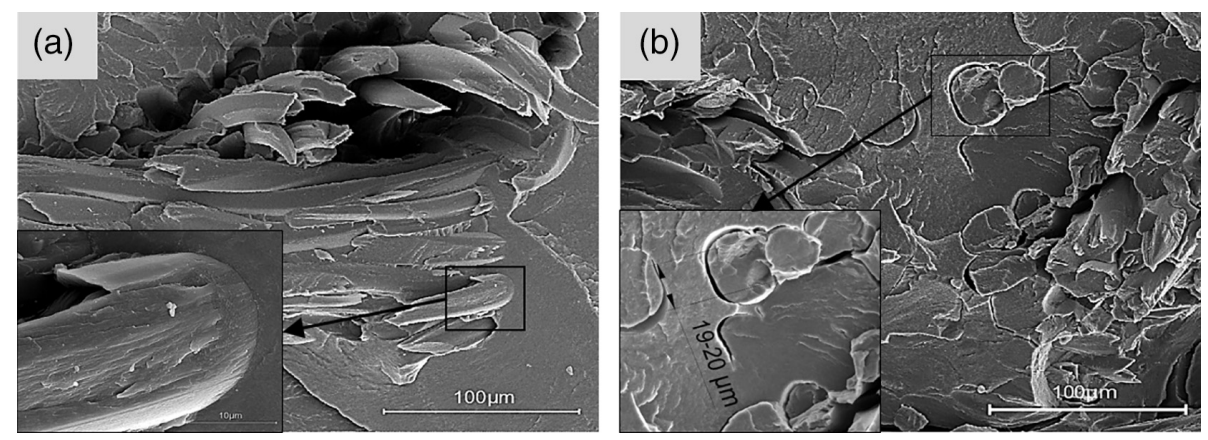

FIG. 9. SEM images after cryofracture of N- and P-composites; (a) P-R-15 and (b) N-R-15.

these broad transitions can be related to the presence of oligomeric PA6 formed during the NYRIM process. These oligomers only form when the in-mold bulk AAROP is carried out in the presence of the textile structures and not in their absence, since in the case of the NN curve (Fig. 10a, Curve 1) such low-temperature transition is absent. The supposed formation of oligomers can be an indication that the textile structures inhibit the bulk AAROP due to some surface finish that was not removed during the textile pre-treatment with acetone. The weak interface at the filament/matrix interface evidenced by SEM and PLM (Fig. 9b) can also be related with excess oligomer content in all N-composites.

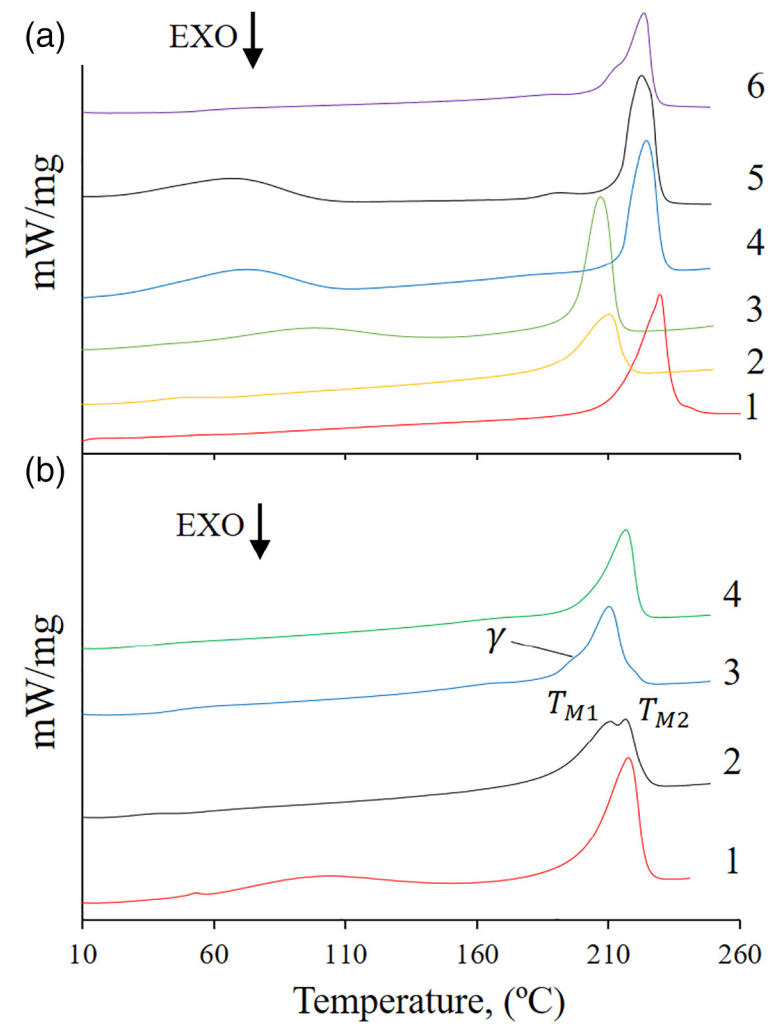

FIG. 10. (a) DSC scans of: 1-NN; 2-PN; 3-MPs; 4-J; 5-first scan J-A; 6-second scan J-A; (b) DSC scan of KSPC: 1-N-J-15 (first scan); 2-P-J-15 (first scan); 3-N-J-15 (second scan); 4-P-J-15 (second scan). For sample designation see Table 2 .
To verify the hypothesis about oligomer formation, NYRIM laminate SPC were extracted with ethanol in a Soxhlet attachment until constant weight, which produced a decrease in weight of $1-2 \%$ for the NN plate and up to $8 \%$ for the N-J-25 composite. This finding is in good agreement with all the above mechanical testing data and explains the inferior mechanical properties of the $\mathrm{N}$ composites compared with the P-composites (Table 3). Let's remind that the anionic PA6 MPs used in the PCCM methods to prepare KSPC do not contain oligomers since they are eliminated in the stage of MPs purification.

Analyzing the DSC curves of both types of KSPC in Fig. 10b shows that the melting peak of the PCCM materials during the first and second scans contain low- and high temperature shoulders. Although in the first scan these shoulders could be related to the melting of PA6 originating from the matrix and textile structures respectively, during the second scan the dual melting behavior could be rather associated with the well-known $\alpha-\gamma$ polymorphism in PA6.

The glass transition temperatures $T_{\mathrm{g}}$, the melting temperatures $T_{\mathrm{m}}$ and crystallinity indices $X_{\mathrm{c}}^{\mathrm{DSC}}$ of all KSPC are tabulated in Table 4. For comparison, DSC data of the precursors and the neat matrices are also given. Due to the relatively faster cooling down during the compression molding, the $X_{\mathrm{c}}^{\mathrm{DSC}}$ of PN becomes lower than that of MPs. The crystallinity of the NN matrix is $43 \%$ that is,

TABLE 4. Crystallinity index $X_{\mathrm{c}}^{\mathrm{DSC}}$ for KSPC and their components.

\begin{tabular}{lcllc}
\hline Sample designation & $T_{g}\left({ }^{\circ} \mathrm{C}\right)^{\mathrm{a}}$ & $T_{m 1}\left({ }^{\circ} \mathrm{C}\right)$ & $T_{m 2}\left({ }^{\circ} \mathrm{C}\right)$ & $X_{c}^{D S C}, \%$ \\
\hline MPs & 32.3 & 207.8 & - & 34.9 \\
PN & 33.3 & 210 & - & 27.5 \\
NN & 47,1 & - & 218.8 & 43.0 \\
J-A & 57.0 & - & 223.5 & 41.9 \\
R-A & 56.5 & - & 223.2 & 46.0 \\
P-J-15 & 30.3 & 210.2 & 216.5 & 31.0 \\
P-R-15 & 32.3 & 208.2 & 217.8 & 30.9 \\
N-J-15 & 29.9 & - & 216.6 & 26.0 \\
N-R-15 & 30.7 & - & 218.3 & 25.5 \\
& & & & \\
\hline
\end{tabular}

For sample designation see Tables 1 and 2

$T_{\mathrm{g}}$ determined during the second DSC scan. 
significantly higher than in the PN matrix (33\%) resulting from the much lower cooling rate and better temperature control during the in-mold NYRIM process that permits the formation of more crystalline phase. As regards the textile-reinforced KSPC; however, the P- and N-composites display similar degree of crystallinity in the $30-32 \%$ range.

Table 4 shows also that the $T_{\mathrm{g}}$ of the two textile structures after annealing lie between 56 and $57^{\circ} \mathrm{C}$, while the $T_{\mathrm{g}}$ of all KSPC are between 30 and $33^{\circ} \mathrm{C}$. This observation indicates higher segmental mobility of the polymer chains in the amorphous fractions of the anionic matrices of both types as compared with those in the knitted textile reinforcements. A possible reason could be the higher crystallinity indices of the latter and the orientation of the textile monofilaments.

Structural Studies by X-Ray Diffraction. To better understand the differences and similarities between the PA6 matrix and reinforcement in KSPC and their precursors, X-ray diffraction studies were performed. The linear diffraction patterns of representative samples were collected and deconvoluted by peak fitting. Equation 3 was implemented to calculate the total crystallinity index and the specific content of $\alpha$ - and $\gamma$-PA6 polymorphs. According to previous findings [26], a monoclinic unit cell lattice was assumed for the $\alpha$-PA 6 form characterized by two peaks corresponding to $\alpha[200]$ and $\alpha[002 / 202]$ crystalline planes with $2 \theta$ being centered in the studied samples at ca. 20 and $23^{\circ}$, respectively. For the $\gamma$-crystalline form, a pseudo-hexagonal unit cell was supposed for all samples, as suggested by Samon et al. [33]. Therefore, it fits with two Gaussian peaks corresponding to $\gamma[001]$ and $\gamma[200]$ crystalline planes were performed with $2 \theta$ being between 21 and $22^{\circ}$. The diffuse scattering of the amorphous PA6 component was presented by two wide Gaussian peaks (halos). This procedure led to good fits with fitting coefficients $r^{2}>0.99$.

Representative X-ray patterns and their deconvolutions are shown in Fig. 11a-d. It can be seen that all PA6 textile structures and neat matrices contain the dual peaks for the $\alpha$-polymorph $(\alpha[200]$ and $\alpha[002 / 202])$ and the two peaks for the $\gamma[001]$ and $\gamma[200]$ planes. In addition to this, the PN neat matrix (Fig. 11a) and J-A (Fig. 11c) contain a clear reflection attributable to the $\gamma[020]$ plane situated between 10 and $15^{\circ}$. As Fig. 11c shows, the $\alpha$-PA6 polymorphs are fitted with symmetric crystalline peaks, which is typical for oriented PA6 [26]. It should be noted also that in the PN (Fig. 11a) and NN (Fig. 11b) samples the $\alpha[200]$ reflection is weaker than the $\alpha[002 / 202]$ peak. This indicates that during the crystallization of the respective PA6 material, the $\alpha$-crystallites display a decreased growth along the plane determined by the weaker intermolecular van der Waals forces.

The fitted WAXS patterns of a P-composites with $15 \%$ fiber content is presented in Fig. 11d. The pattern deconvolution allowed a separation of the $\alpha[200]$ and $\alpha[002 / 202]$ reflections of the anionic matrix PA6 obtained by PCCM

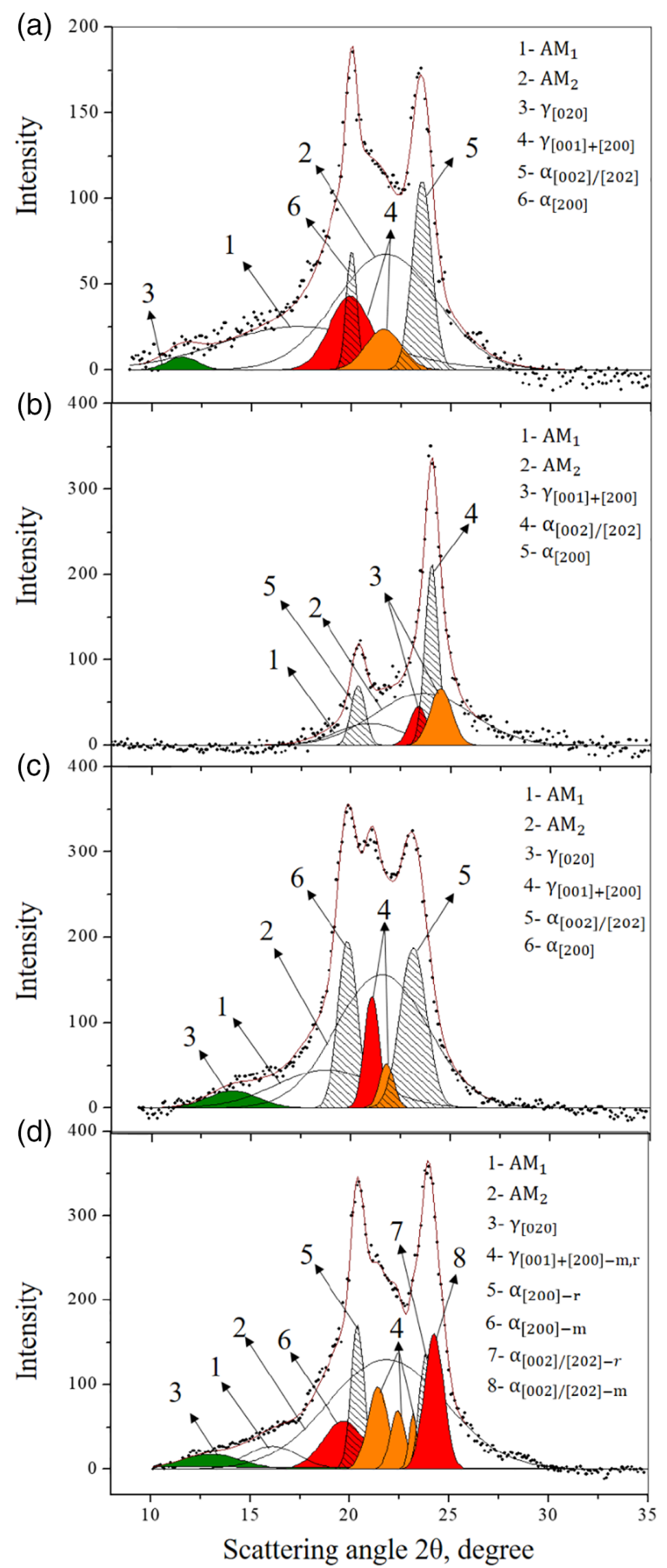

FIG. 11. WAXS patterns and their fits of KSPC building components: (a) PN; (b) NN; (c) J-A. WAXS patterns and their fits of KSPC: (d) P-J-15. For sample designations see Table 2. $\mathrm{AM}_{1}$ and $\mathrm{AM}_{2}=$ diffuse peaks of the amorphous PA6.

and the hydrolytic PA6 of the textile structures. For the peaks of the two $\gamma$-polymorphs, however, such separation was impossible. The $\alpha$-PA6 matrix peaks are wider than those of the textile reinforcements. This means that the anionic PA6 matrix material formed during the PCCM process consists of less perfect and non-oriented crystallites, while the PA6 from the knitted textile filaments did not melt, remaining oriented. 
Table 5 shows the crystalline phase separation and the degree of crystallinity $X_{\mathrm{c}}^{\mathrm{WAXS}}$ of N- and P-composites. As seen from Table 5, the $X_{\mathrm{c}}^{\mathrm{WAXS}}$ values of the stretched and annealed textile structures R-A and J-A of ca. 53\% are significantly higher than those of the neat PA6 plates obtained by either NYRIM or PCCM and the P-composites. The N-composites displayed slightly higher crystallinity indices, approaching 50\%. The rate of cooling in the semiautomatic NYRIM mold is lower than in compression molding, which determines the higher $X_{\mathrm{c}}^{\mathrm{WAXS}}$ values in the former case.

The relationship between the $\alpha$ - and $\gamma$-crystalline phases seems to be also affected by the different thermal regimes and orientation of the samples. Higher $\alpha / \gamma$ ratios of ca. 4.0 are observed in the R-A and J-A textile structures. Apparently, their orientation and the lack of melting during their annealing promote the creation of $\alpha$-PA6 polymorph. At the same time, in the neat $\mathrm{PN}$ and $\mathrm{NN}$ samples the fraction of the $\alpha$-PA6 is much lower, especially in PN, wherein an equilibrium between the two PA6 polymorphs is observed. This effect is explained with the melting of the MPs and their relatively fast cooling down before demolding.

Notably, in all of KSPC samples the two $\alpha$-reflections of the textile structures have become asymmetric, with the $\alpha[002 / 202]$ peak becoming stronger. Since no melting of the reinforcing monofilament occurred, as shown by the microscopy study above, recrystallization of matrix PA6 upon the oriented textile filaments during the laminate consolidation can be hypothesized with a preferred growth of the $\alpha$-crystallites along the direction of the plane of the strong intra sheet H-bonding. This is one more proof, although indirect, for the possibility of TCL formation during the KSPC preparation by either NYRIM or PCCM.

In the P-composites, the $\alpha / \gamma$ ratio is closing or slightly above 2.0, while in the $\mathrm{N}$-composites it is in the 2.5-3.3 range. Again, this should be attributed to the different temperature profiles in the NYRIM and PCCM process. Also, in the compression molding technique one deals with melting of already existing PA6, whereas in the NYRIM technology the PA6 matrix is formed in situ and only crystallizes during the process, without any melting. This causes the higher values of the total crystallinities and the $\alpha$-polymorph content in the latter case.

Table 5 also presents the values of the evolution of the d-spacings of all neat PA6 samples obtained by PCCM and NYRIM and in the respective laminates containing 15\% RA and J-A structures. Quite notably, the $\mathrm{d}_{\gamma(020)}$ of the Pcomposites varying between $6.0-6.6 \AA$ is lower than the respective values of the NYRIM materials being in the range of 7.0-7.3 $\AA$. With the other long spacings the differences are smaller. Apparently, the crystalline cell type and dimensions are not strongly affected by the parameters of the consolidation techniques. It should be noted that in many cases in Table 5, it was possible to distinguish the crystalline planes of the PA6 matrix obtained by NYRIM or PCCM and those of the oriented PA6 from the reinforcements. Unfortunately, having in mind that the WAXS patterns in this study are produced by standard WAXS equipment with a certain level of noise, the differences between the d-values of the matrix and reinforcement PA6 are too small to be interpreted.

\section{CONCLUSIONS}

Single polymer laminate composites based on anionic PA6 matrix and reinforced by PA6-knitted textile structures were successfully prepared by two techniques: (1) a combination of powder-coating of PA6 knitted textile structures with PA6 MPs and subsequent consolidation by compression molding (PCCM process), and by (2) RIM including the in-mold preparation of the PA6 matrix, in the presence of the same knitted textiles (NYRIM process). The PA6

TABLE 5. Data from the deconvolution of the WAXS patterns of KSPC, textile structures and anionic PA6 precursors.

\begin{tabular}{|c|c|c|c|c|c|c|c|c|c|}
\hline Sample & $X_{\mathrm{c}}^{\mathrm{WAXS}}(\%)$ & $\alpha(\%)$ & $\gamma(\%)$ & $\frac{\alpha}{\gamma}$ & $d_{\alpha(200)}(\AA)$ & $d_{\alpha(002) /(202)}(\AA)$ & $d_{\gamma(020)}(\AA)$ & $d_{\gamma(001)}(\AA)$ & $d_{\gamma(200)}(\AA)$ \\
\hline PN & 34.9 & 17.4 & 17.5 & 1.00 & 4.32 & 3.68 & 7.48 & 4.33 & 4.00 \\
\hline NN & 44.8 & 28.3 & 16.5 & 1.72 & 4.24 & 3.60 & - & 3.70 & 3.53 \\
\hline $\mathrm{J}-\mathrm{A}$ & 52.8 & 41.0 & 11.8 & 3.47 & 4.35 & 3.74 & 6.13 & 4.10 & 3.96 \\
\hline $\mathrm{R}-\mathrm{A}$ & 53.6 & 42.9 & 10.7 & 4.00 & 4.24 & 3.68 & 6.97 & 4.04 & 3.93 \\
\hline P-J-15 & 45.9 & $\begin{array}{l}18.0^{\mathrm{R}} \\
13.0^{\mathrm{M}} \\
\mathbf{3 1 . 0}^{\mathbf{T}}\end{array}$ & 14.9 & 2.08 & $\begin{array}{l}4.38^{\mathrm{R}} \\
4.23^{\mathrm{M}}\end{array}$ & $\begin{array}{l}3.57^{\mathrm{R}} \\
3.63^{\mathrm{M}}\end{array}$ & 6.57 & 4.03 & $\begin{array}{l}3.86^{\mathrm{R}} \\
3.73^{\mathrm{M}}\end{array}$ \\
\hline P-R-15 & 43.7 & $\begin{array}{l}8.7^{\mathrm{R}} \\
19.7^{\mathrm{M}} \\
\mathbf{2 8 . 4 ^ { \mathrm { T } }}\end{array}$ & 15.3 & 1.86 & $\begin{array}{l}4.41^{\mathrm{R}} \\
4.25^{\mathrm{M}}\end{array}$ & $\begin{array}{l}3.51^{\mathrm{R}} \\
3.63^{\mathrm{M}}\end{array}$ & 6.06 & 4.04 & $\begin{array}{l}3.94^{\mathrm{R}} \\
3.75^{\mathrm{M}}\end{array}$ \\
\hline N-J-15 & 50.9 & $\begin{array}{l}21.8^{\mathrm{R}} \\
17.2^{\mathrm{M}} \\
\mathbf{3 9 . 0}^{\mathrm{T}}\end{array}$ & 11.9 & 3.27 & $\begin{array}{l}4.45^{\mathrm{R}} \\
4.60^{\mathrm{M}}\end{array}$ & $\begin{array}{l}3.75^{\mathrm{R}} \\
3.67^{\mathrm{M}}\end{array}$ & 7.32 & $\begin{array}{l}4.25^{\mathrm{R}} \\
4.20^{\mathrm{M}}\end{array}$ & $\begin{array}{l}4.05^{\mathrm{R}} \\
-\end{array}$ \\
\hline N-R-15 & 47.4 & $\begin{array}{l}19.8^{\mathrm{R}} \\
15.3^{\mathrm{M}} \\
\mathbf{3 4 . 1 ^ { \mathrm { T } }}\end{array}$ & 13.3 & 2.56 & $\begin{array}{l}4.43^{\mathrm{R}} \\
4.54^{\mathrm{M}}\end{array}$ & $\begin{array}{l}3.76^{\mathrm{R}} \\
3.68^{\mathrm{M}}\end{array}$ & 7.02 & $\begin{array}{l}3.97^{\mathrm{R}} \\
4.31^{\mathrm{M}}\end{array}$ & $\begin{array}{l}3.84^{\mathrm{R}} \\
4.19^{\mathrm{M}}\end{array}$ \\
\hline
\end{tabular}

For sample designation see Tables 1 and 2 .

$\mathrm{R}$, Reinforcement; M, Matrix; T, Total. 
MPs for PCCM were prepared by anionic polymerization in suspension prior to compression molding. In the NYRIM process, a similar anionic polymerization process was applied but carried out in situ in the bulk and directly in the NYRIM mold, in the presence of the respective textile reinforcements. The influence of reinforcement architecture (R-A and $\mathrm{J}-\mathrm{A}$ ), $\mathrm{V}_{\mathrm{f}}$ (varying in the $15-25 \%$ range), and reinforcement orientation (wale and course directions) on the tensile properties of KSPC was evaluated for both molding techniques.

It was found out that the PCCM process can produce single polymer laminates with good mechanical properties in tension, reaching $E$ - and $\sigma_{\max }$ values of $1.93 \mathrm{GPa}$ and 67.8 $\mathrm{MPa}$, respectively, meaning relative improvements of 12 and $18 \%$ as compared with the neat PA6 prepared from MPs. These results were produced with composites from the Pcomposites containing $15 \%$ and $25 \mathrm{vol} \%$ of R-A textiles. Increasing the $V_{\mathrm{f}}$ did not significantly improve the E-modulus. The NYRIM technique produced laminates with lower stiffness and strength, the reason being the formation of oligomers in the presence of the knitted textile reinforcements. This technique is advantageous for the preparation of neat PA6 plates.

The microscopy results and indirectly the WAXS studies suggested the formation of a TCL at the fiber-matrix interface in both NYRIM and PCCM material, it being slightly thicker in the latter case. Structural studies by thermal methods and WAXS indicated the importance of the stretch-annealing of the textile reinforcements and of the temperatures for sample consolidation in both processes.

Further improvement of the KSPC mechanical behavior will require novel reinforcements' architecture, e.g. the use of woven textiles, optimization of their surface finishing and studying the interlaminar shear strength of the KSPC as a function of ply the amount and alignment.

\section{ACKNOWLEDGEMENTS}

This work was partially financed by FEDER funds through the COMPETE program and by national funds through FCT - Foundation for Science and Technology within the project POCI-01-0145-FEDER-007136. SDT thanks FCT for his PhD Grant SFRH/BD/94759/2013. NVD thanks for the financial support of FCT in the frames of the strategic project UID/CTM/50025/2013. Finally, ZZD is thankful to FCT for the SFRH/BSAB/130271/2017 personal research grant. All authors gratefully acknowledge the support of the project TSSiPRO-NORTE-01-0145FEDER-000015 funded by the regional operational program NORTE 2020, under the PORTUGAL 2020 Partnership Agreement, through the European Regional Development Fund.

\section{REFERENCES}

1. K. P. Matabola, A. R. Vries, F. S. Moolman, A. S. Luyt, J. Mater. Sci. 2009, 44, 6213
2. N. Capiati, R. Porter, J. Mater. Sci. 1975, 10, 1671.

3. O. A. Khondker, T. Fukui, M. Inoda, A. Nakai, H. Hamada, Compos. Part A Appl. Sci. Manuf. 2004, 35, 1195.

4. D. Yao, R. Li, P. Nagarajan, Polym. Eng. Sci. 2006, 46, 1223.

5. F. P. La Mantia, D. Curto, R. Scaffaro, J. Appl. Polym. Sci. 2002, 86, 1899.

6. F. V. Lacroix, M. Werwer, K. Schulte, Compos. Part A Appl. Sci. Manuf. 1998, 29, 371.

7. P. J. Hine, A. Astruc, I. M. Ward, J. Appl. Polym. Sci. 2004, 93, 796.

8. I. M. Ward, P. J. Hine, Polymer. 2004, 45, 1413.

9. Y. Gong, G. Yang, J. Appl. Polym. Sci. 2010, 118, 3357.

10. D. Bhattacharyya, P. Maitrot, S. Fakirov, Express Polym Lett. 2009, 3, 525.

11. B. Alcock, N. O. Cabrera, N.-M. Barkoula, Z. Wang, T. Peijs, Compos. Part B Eng. 2008, 39, 537.

12. J. Karger-Kocsis, T. Bárány, Compos. Sci. Technol. 2014 , 92, 77.

13. T. Ageyeva, I. Sibikin, J. Karger-Kocsis, Polymers (Basel). 2018, 10, 357.

14. H. Sekiguchi, B. Coutin, J. Polym. Sci. Polym. Chem. Ed. 1973, 11, 1601.

15. P. Dubois, O. Coulembier, J.-M. Raquez, Handbook of Ring-Opening Polymerization, John Wiley \& Sons, Weinheim, 2009.

16. Y. Gong, A. Liu, G. Yang, Compos. Part A Appl. Sci. Manuf. 2010, 41, 1006.

17. N. Dencheva, Z. Denchev, A. S. Pouzada, A. S. Sampaio, A. M. Rocha, J. Mater. Sci. 2013, 48, 7260.

18. N. Dencheva, D. Vale, Z. Denchev, Polym. Eng. Sci. 2017, 57, 806 .

19. N. Dencheva, Z. Denchev, S. Lanceros-Méndez, T. Ezquerra Sanz, Macromol. Mater. Eng. 2016, 301, 119.

20. N. Dencheva, A. S. Sampaio, F. M. Oliveira, A. S. Pouzada, A. M. Brito, Z. Denchev, J. Appl. Polym. Sci. 2014, 131, 40083.

21. C. Brêda, N. Dencheva, S. Lanceros-Méndez, Z. Denchev, J. Mater. Sci. 2016, 51, 10534.

22. F. Oliveira, N. Dencheva, P. Martins, S. Lanceros-Méndez, Z. Denchev, Express Polym. Lett. 2016, 10, 160.

23. M. A. Rahman, L. A. Renna, D. Venkataraman, P. Desbois, A. J. Lesser, Polymer 2018, 138, 8.

24. A. Brent Strong, Fundamentals of Composites Manufacturing: Materials, Methods and Applications, Society of Manufacturing Engineers, Michigan (2008).

25. Y. P. Khanna, W. P. Kuhn, J. Polym. Sci. Part B Polym. Phys. 1997, 35, 2219.

26. N. Dencheva, T. Nunes, M. J. Oliveira, Z. Denchev, Polymer. $2005,46,887$.

27. G. Rusu, K. Ueda, E. Rusu, M. Rusu, Polymer. 2001, 42 , 5669.

28. F. Dan, C. Vasiliu-Oprea, Colloid Polym. Sci. 1998, 276, 483

29. C. Vasiliu-Oprea, F. Dan, J. Appl. Polym. Sci. 1996, 62, 1517 
30. N. Dencheva, H. Gaspar, S. Filonovich, O. Lavrova, T. Busani, G. Bernardo, Z. Denchev, J. Mater. Sci. 2014, 49, 4751.

31. H. Quan, Z.-M. Li, M.-B. Yang, R. Huang, Compos. Sci. Technol. 2005, 65, 999.
32. N. Dencheva, A. Stribeck, Z. Denchev, Eur. Polym. J. 2016, 81, 447.

33. J. M. Samon, J. M. Schultz, B. S. Hsiao, Polymer. 2000, 41, 8887. 